\title{
ESTIMATIVA DO MÓDULO DE ELASTICIDADE EM VIGAS LAMINADAS COLADAS PELOS MÉTODOS ESTÁTICO E DINÂMICO
}

\author{
Alexsandro Bayestorff da Cunha ${ }^{1}$, Jorge Luís Monteiro de Matos ${ }^{2}$ \\ ${ }^{1}$ Eng. Florestal, Dr., UnC, CAV/UDESC, Lages, SC, Brasil - a2abc@ cav.udesc.br \\ ${ }^{2}$ Eng. Florestal, Dr., Depto. de Engenharia e Tecnologia Florestal, UFPR, Curitiba, PR, Brasil - jmatos.ufpr@gmail.com
}

Recebido para publicação: 14/10/2008 - Aceito para publicação: 07/06/2010

\begin{abstract}
Resumo
O objetivo do estudo foi estabelecer um modelo de equação linear para estimativa do módulo de elasticidade real de vigas laminadas coladas, a partir do módulo de elasticidade das lamelas pelo método do Stress Wave Timer e montagem das vigas pelo método de classificação das lamelas. $\mathrm{O}$ trabalho foi desenvolvido utilizando-se peças de madeira serrada de Pinus taeda e adesivo melamina ureia formaldeído. O processo de fabricação das vigas envolveu classificação das peças, usinagem de emendas, formação das lamelas, montagem e prensagem das vigas. Já os ensaios envolveram a determinação do módulo de elasticidade através do Stress Wave Timer e por meio de uma máquina de ensaios. Os resultados foram analisados através da análise da regressão, para o estabelecimento da equação de ajuste de correlação. Concluiu-se que o sistema de classificação visual utilizado na seleção de peças foi insuficiente para se atingir os valores máximos de módulo de elasticidade; o posicionamento das lamelas através do método dinâmico de classificação teve como consequência o aumento médio do módulo; e que o modelo de regressão não se mostrou adequado para o estabelecimento de predições do módulo de elasticidade real das vigas.

Palavras-chave: Madeira laminada colada; ensaios estáticos e dinâmicos, melamina ureia formaldeído.
\end{abstract}

\begin{abstract}
Estimate of elasticity module in glulam beams for static and dynamic methods. This study aimed to establish a model of linear equation to estimate the true elasticity module, the glulam beams, from the elasticity module of the layers by the method of Stress Wave Timer and composition of beams by the classification of layers. The work was developed, using pieces of saw wood of Pinus taeda and adhesive melamine urea formaldehyde. The beam fabrication process concerned the classification of the pieces, correction machining and layers formation, as well as the assemblage and pressurization of the beams. The assays, nevertheless, involved the determination of the elasticity module through the Stress Wave Timer and through the use of a machine of assays. The results were analyzed through the regression analysis for the establishment of the equation of adjusting the correlation. It was concluded that the classification system used to select pieces was insufficient to obtain the maximum values of the modulus of elasticity; the positioning of lamellas through the method of dynamic classification had as a consequence the medium increase of the module; and the regression model was not suitable for the establishment of predictions of the real elasticity module of beams.

Keywords: Glulam; static and dynamic tests; melamine urea formaldehyde
\end{abstract}

\section{INTRODUÇÃO}

Viga laminada colada pode ser definida como uma peça estrutural formada por duas ou mais peças de madeira, unidas por adesivo. As lâminas podem ser coladas na horizontal ou na vertical, formando laminados horizontais e verticais, respectivamente. O laminado horizontal é o mais utilizado, por não apresentar limitação em altura, além de possibilitar a construção de peças curvas (LAHR, 1983).

Natterer (1991) afirma que uma das características da MLC é a versatilidade na obtenção das mais variadas formas geométricas para elementos estruturais. As possibilidades arquitetônicas daí 
resultantes são inúmeras e dependem principalmente da indispensável colaboração entre arquitetos e engenheiros. Têm-se como principais vantagens, de acordo com o autor:

- facilidade na construção de grandes estruturas a partir de peças de dimensões comerciais;

- redução de rachaduras e outros defeitos de peças maciças de madeira com grandes dimensões;

- possibilidade de emprego de peças de qualidade inferior em zonas menos solicitadas;

- baixa relação peso/resistência, não exigindo equipamentos possantes para içamento;

- bom desempenho sob a ação do fogo, em razão de seções transversais avantajadas.

A MLC tem seus usos mais frequentes em estruturas de cobertura, elementos estruturais principais para pontes, torres de transmissão, edifícios, embarcações, banzos de escadas e corrimão, equipamentos decorativos planos ou em relevo, esquadrias e móveis. Isso se deve ao fato da MLC adaptar-se a uma significativa variedade de formas e apresentar alta resistência a solicitações mecânicas, em função de seu peso próprio relativamente baixo (ZANGIÁCOMO, 2003).

O sucesso do uso das vigas laminadas coladas está intimamente ligado ao adesivo empregado na sua construção e a classificação das peças que serão distribuídas na estrutura. $\mathrm{O}$ adesivo deve possuir características de uma união resistente, estável e durável, mas não se devendo esquecer que essas características relacionam-se diretamente com as propriedades da madeira. Dessa forma, as resinas mais utilizadas para uso estrutural em madeiras são as resinas fenólica e melamínica com suas modificações. As resinas epóxi possuem características muito úteis, mas não são utilizadas devido ao seu custo. Atualmente se está fazendo uso das resinas de poliuretano.

\section{Classificação de madeiras}

De acordo com PLESSEY TELECOMMUNICATIONS (1973), citado por Carreira (2003), em 1958, institutos de pesquisas em madeira da Inglaterra, Austrália e América do Norte descobriram que a resistência e a rigidez à flexão da madeira são altamente correlacionadas. Eles verificaram que a rigidez (MOE) de uma peça de madeira serrada pode ser um forte indicador de sua resistência.

Para a classificação estrutural de peças de madeira através de processos dinâmicos, são utilizados dois métodos: visual e mecânico. Na classificação visual da madeira, o classificador examina cada peça e limita o tipo, localização e tamanho dos vários defeitos que podem afetar a resistência estrutural. A classificação mecânica consiste em determinar o módulo de elasticidade longitudinal das lâminas por um meio dinâmico. Entre esses métodos, podem-se destacar flexão estática, MSR (Machine Stress Rating), método da vibração transversal, stress wave e ultrassom.

A classificação visual é baseada nas características de crescimento relacionadas aos critérios de medição estabelecidos na norma ASTM D245-93 (1998) e incorporados pelo SPIB (Southern Pine Inspection Bureau) para a elaboração de suas regras de classificação visual, assim como fazem as outras agências de classificação norte-americanas. Tais características são: inclinação das fibras, nós (em caibros e pranchas, em vigas e longarinas, em postes e colunas, em tábuas), racha anelar e fenda, empenamento e densidade.

A classificação mecânica através do Stress Wave Method é uma técnica que vem sendo investigada há mais de 30 anos e tem sido utilizada para diversas aplicações na indústria de produtos florestais, consistindo na aplicação de uma onda de tensão (impacto) no material e na análise do fenômeno de propagação desse estímulo. A velocidade de propagação de uma onda de tensão induzida e sua atenuação no material são os principais parâmetros analisados nesses casos (TARGA et al., 2005).

\section{Aspectos técnicos da construção de vigas estruturais de madeira laminada colada}

Pesquisas desenvolvidas mostram que para os elementos estruturais em madeira laminada colada devem ser utilizadas espécies de madeira que apresentem densidade compreendida entre $0,40 \mathrm{~g} / \mathrm{cm}^{3} \mathrm{e}$ $0,75 \mathrm{~g} / \mathrm{cm}^{3}$. As espécies mais indicadas são as madeira do gênero Pinus spp. que, segundo a norma NBR 7190 (1997) - Projeto de Estruturas de Madeira, apresentam densidade em torno de 0,5 g/ $\mathrm{cm}^{3}$. Madeiras que apresentem coeficientes de retração muito diferentes segundo as direções radial e tangencial não devem ser utilizadas na composição (FIORELLI, 2005).

Produção das lâminas

Com relação à espessura das tábuas que serão utilizadas no composto, Matos (2000) cita que o uso de tábuas de maior espessura é mais econômico porque se terá menor consumo de adesivo, menor número de horas trabalhadas e economia do material. Por razões tecnológicas, a espessura é limitada a 
$50 \mathrm{~mm}$. A limitação no uso de tábuas de maior espessura deve-se a dificuldades de secagem, principalmente.

De acordo com Szücs (1992), as peças a serem utilizadas no composto devem apresentar teor de umidade entre 7 e 14\%. Freas; Selbo (1954) consideram satisfatório um teor de umidade de 8 a $10 \%$ para colagem de vigas de uso interior e de 12 a $15 \%$ para uso exterior. Ambos salientam que é importante não haver diferença entre teor de umidade de tábuas adjacentes de mais de $5 \%$.

\section{Classificação das lâminas}

No processo de classificação das lâminas, a ASTM D 3737 (1996) cita que a adoção de critérios para a classificação das lâminas e posterior posicionamento na viga, colocando-se as de melhor qualidade nas faces mais externas e as de qualidade inferior próximas à linha neutra, garante um aumento da resistência e da rigidez dos elementos estruturais. Deve-se evitar a disposição de lâminas orientadas em sentido radial e tangencial dentro da mesma viga, em função da retratibilidade diferenciada das peças. Associando-se as informações das características visuais da madeira com as de módulo de elasticidade, pode-se melhorar substancialmente o desempenho das estruturas.

Fabricação das emendas

As emendas representam uma descontinuidade do material e consequentemente são regiões consideradas potencialmente fracas. Desse modo, as emendas em MLC representam um dos mais importantes fatores das características de resistência e elasticidade dos elementos estruturais de MLC. Três são os tipos mais comuns de emendas longitudinais em MLC: topo, bisel e dentada. Alguns dos fatores que regem a utilidade dessas emendas são a resistência, a facilidade e economia de produção, a aparência (e para o caso da MLC, principalmente) e a uniformidade de desempenho (MACEDO; CALIL JÚNIOR, 1999).

Atualmente, recomenda-se a utilização das emendas dentadas por parte dos produtores de madeira laminada colada, devido ao fato de ela reunir condições de resistência e praticidade de produção.

Segundo Selbo (1963), para se atingir a mais alta resistência da emenda dentada, a ponta dos dentes deve ser tão fina quanto possível. A relação comprimento/largura deve ser consideravelmente grande, de maneira a garantir uma adequada área de cola da emenda, desenvolvendo assim a resistência necessária ao cisalhamento. Outro fator que deve ser levado em consideração para garantir a qualidade do produto de madeira laminada colada refere-se ao espaçamento entre as emendas. Para as emendas de lâminas adjacentes, Szücs (1992) recomenda que nas lâminas mais externas as emendas de lâminas vizinhas devem ser espaçadas de no mínimo 20 vezes a espessura da lâmina, e que na metade central da peça o espaçamento entre emendas de lâminas vizinhas deve ser de no mínimo 12 vezes a espessura da lâmina.

Hernandez (2002) citado por Fiorelli (2005) recomenda um espaçamento entre emendas de uma mesma lâmina superior a $1800 \mathrm{~mm}$ e para lâminas adjacentes um espaçamento mínimo de $150 \mathrm{~mm}$. A Norma Brasileira NBR 7190 (1997) estabelece um espaçamento mínimo entre emendas adjacentes igual a 25 vezes a espessura da peça.

Aplicação do adesivo e prensagem das vigas

$\mathrm{Na}$ colagem das peças de madeira laminada colada deve-se levar em consideração a pressão a ser aplicada na viga para garantir uma eficiência na colagem das lâminas. Segundo Henrique de Jesus (2000), para madeiras de densidade inferior ou igual a $0,5 \mathrm{~g} / \mathrm{cm}^{3}$, deve-se utilizar uma pressão de colagem igual a $0,7 \mathrm{MPa}$, e para madeira de densidade superior a $0,5 \mathrm{~g} / \mathrm{cm}^{3}$, pressão igual a $1,2 \mathrm{MPa}$, ou então atender a recomendação do fabricante de cola.

Segundo Matos (2000), a pressão aplicada para madeira laminada colada deve ser de $7 \mathrm{kgf} / \mathrm{cm}^{2}$ a $14 \mathrm{kgf} / \mathrm{cm}^{2}$, segundo recomendação do Forest Products Laboratory, de Madison. Essas recomendações têm como finalidade obter uma pressão mínima de colagem, evitando danos à madeira sob altas pressões.

Em não havendo outra indicação para adesivo melamina formaldeído, a prensagem deve ser mantida por um período mínimo de 12 horas, tomando-se por base um ambiente com temperatura de $20{ }^{\circ} \mathrm{C}$ e teor de umidade relativa de $65 \%$. Esse valor pode variar dependendo do tipo de adesivo. Após o período de prensagem, a retirada da pressão deverá ser gradativa e alternada ao longo da peça. 


\section{Hipótese}

Os sistemas de classificação de vigas de madeira laminada colada pelo método estático, ou seja, pelo processo destrutivo em uma máquina de ensaios, e através do processo dinâmico do Stress Wave Timer apresentam uma alta correlação no que tange à variável módulo de elasticidade. Outrossim, no processo de classificação das lamelas utilizadas nas vigas, há uma grande influência do posicionamento dessas lamelas nos valores de rigidez das vigas, tendo em vista que lamelas com maior rigidez devem ser colocadas nas zonas de tração e compressão da viga.

\section{Objetivo}

O objetivo do estudo foi estabelecer um modelo de equação linear para estimativa do módulo de elasticidade real de vigas laminadas coladas, determinado em ensaio estático, a partir do módulo de elasticidade das lamelas pelo método dinâmico do Stress Wave Timer e montagem das vigas pelo método de classificação das lamelas. Para tanto, delimitaram-se as seguintes atividades: classificar as peças que fizeram parte da lamela pelo método visual; classificar as lamelas através do Stress Wave Timer, de forma a se determinar o MOE dinâmico para aumentar a rigidez do composto pela distribuição não aleatória das camadas; confeccionar e avaliar vigas estruturais de madeira laminada colada, de acordo com o processo de classificação da madeira utilizado habitualmente pela empresa; estimar o módulo de elasticidade dinâmico da viga e ensaiar as vigas em uma máquina universal de ensaios, de modo a estabelecer correlações entre as duas formas de obtenção da variável.

\section{MATERIAL E MÉTODOS}

O processo de confecção das vigas estruturais de madeira laminada colada foi desenvolvido na Battistella Indústria e Comércio Ltda., situada no município de Lages, SC. Já os ensaios tecnológicos foram realizados no Laboratório de Tecnologia da Madeira da Escola de Florestas da Universidade Federal do Paraná. Para a confecção das vigas estruturais, foram utilizadas 300 peças de madeira serrada provenientes de reflorestamentos de Pinus taeda da Empresa, que apresentavam inicialmente $32 \mathrm{~mm} \mathrm{X} 128 \mathrm{~mm}$ X $2050 \mathrm{~mm}$ de dimensões nominais e teor de umidade médio de $12 \%$; e adesivo melamina ureia formaldeído com catalisador (MUF 1242 / 2542), sistema líquido/líquido da Akzo Nobel.

\section{Delineamento experimental}

O delineamento experimental envolveu a confecção de 10 vigas estruturais de madeira laminada colada com $3100 \mathrm{~mm}$ de comprimento, $122 \mathrm{~mm}$ de largura e $156 \mathrm{~mm}$ de altura. As vigas foram compostas por 6 peças de madeira serrada aplainadas e emendadas com dimensões de $3100 \mathrm{~mm}$ de comprimento, $122 \mathrm{~mm}$ de largura e $26 \mathrm{~mm}$ de espessura. A análise estatística dos dados coletados através dos ensaios foi realizada por meio da análise da regressão, para o estabelecimento da equação de ajuste de correlação.

\section{Processo de construção das vigas estruturais}

A sequência de operações durante a confecção das vigas estruturais foi iniciada pelo prébitolamento das peças de madeira serrada, passando pela classificação e destopo, processo de emenda finger-joint para a formação das lamelas, aplainamento, composição das vigas de acordo com a distância mínima exigida entre as emendas, aplicação de adesivo, prensagem, embalagem.

\section{Pré - Bitolamento}

Todas as peças de madeira serrada passaram inicialmente pelo processo de pré-bitolamento em uma plaina de 4 faces, com o intuito de facilitar a visualização dos defeitos na classificação visual das peças que fizeram parte da composição das vigas. As peças que inicialmente apresentavam dimensões nominais de $32 \mathrm{~mm}$ X $128 \mathrm{~mm}$ X $2050 \mathrm{~mm}$, passaram a ter $30 \mathrm{~mm}$ X $126 \mathrm{~mm}$ X $2050 \mathrm{~mm}$.

Destopo e classificação

Os processos de destopo e classificação foram feitos conjuntamente. A classificação das peças foi baseada na metodologia utilizada pela empresa para se ter resultados os mais próximos possíveis da realidade, evitando-se também que as peças fossem classificadas por métodos de difícil empregabilidade nas indústrias. 
A metodologia de classificação utilizada na empresa é baseada em um estudo desenvolvido por Carreira (2003), que utilizou os métodos de classificação do SPIB (1994 e 1999), os quais limitam a presença de defeitos como nós, rachaduras, esmoado e empenamentos, além de agrupar as peças em densas e não densas. Dessa forma, classificaram-se visualmente as peças a serem utilizadas nas vigas observando-se as seguintes características:

- Densidade: as peças foram classificadas em densa (D) com 6 ou mais anéis de crescimento e mais de $1 / 3$ da seção transversal contendo madeira de inverno, ou 4 ou mais anéis de crescimento e mais de $1 / 2$ da seção transversal contendo madeira de inverno; e não densa (ND) para as demais densidades (média e baixa). As peças classificadas como densas foram utilizadas nas camadas inferior e superior das vigas, e as não densas foram utilizadas nas partes internas.

- Presença de defeitos e a densidade das peças: na classe de madeira densa não foram permitidos defeitos como nó solto, nó tipo gravata, nó firme atravessando a peça em espessura, medula nos dois lados da peça, esmoado e rachaduras; já para a classe de madeira não densa não eram permitidos defeitos como nó gravata, nó atravessando a peça em espessura, rachaduras e esmoado.

- Comprimento das peças: além da classificação visual, as peças a serem utilizadas nas extremidades não poderiam ter comprimento inferior a $800 \mathrm{~mm}$, e as do miolo, inferior a $300 \mathrm{~mm}$.

Formação das lamelas e bitolamento

Com a etapa de classificação concluída, realizou-se a etapa de emenda das peças conforme processo habitual da empresa produtora das vigas laminadas, em que o objetivo era a obtenção de lamelas com $3100 \mathrm{~mm}$ de comprimento com o menor número possível de emendas. Obteve-se, então, cerca de 5 emendas por lamela, ou seja, a cada $520 \mathrm{~mm}$ de comprimento aproximadamente, uma emenda dentada vertical tipo finger joint foi feita com $26 \mathrm{~mm}$ de comprimento, conforme recomendação da norma alemã DIN-68-140.

A distância entre as emendas inferior ao recomendado pelas normas técnicas é devido a razões operacionais e para obtenção de rendimento maior na produção das lamelas, tendo em vista que o Pinus taeda é uma espécie que possui entrenós com distâncias de $70 \mathrm{~cm}$, o que dificulta a obtenção de peças isentas de defeitos, especialmente nós, em distâncias e comprimentos maiores. Considerando-se ainda o fato de que próximo à região de nós há desvios de grã, o comprimento máximo das peças para emendas está em torno de $50 \mathrm{~cm}$. Dessa forma, é importante salientar que, ao invés de utilizar lamelas isentas de defeitos com pequeno espaçamento entre as emendas, seria mais interessante ter lamelas com defeitos, que ainda poderiam ser classificadas de acordo com as regras do SPIB, mas com maior espaçamento entre as emendas.

O procedimento de confecção das emendas foi realizado por uma fresadeira dotada de oito jogos de cinco facas, com movimento giratório contínuo, que tinha a função de formar os dentes nas peças de madeira aplainadas, sendo o adesivo aplicado com auxílio de um pincel, com a desvantagem de não se ter o controle efetivo da gramatura. $\mathrm{O}$ adesivo foi preparado na proporção de 100 partes de resina para 20 partes de catalisador, conforme recomendação da empresa fornecedora do material, as quais foram misturadas em um vasilhame no momento do início da aplicação nas peças.

O processo de emenda das peças para a formação da lamela foi realizado em uma emendadeira automática, que aplicava pressão no ponto de encontro dos dentes de duas peças, com o objetivo de fazer a penetração do adesivo na madeira e unir os dentes das extremidades de duas peças. Dessa forma, ao final da união, a peça deslizava em uma esteira até a finalização do comprimento da lamela, sendo destopada em $3100 \mathrm{~mm}$ e colocada em uma grade com separadores, permanecendo em repouso para ocorrer a etapa de pós-catalisação durante 5 dias, conforme recomendação.

Determinação do módulo de elasticidade dinâmico das lamelas por emissão de ondas acústicas

Antes da realização do ensaio, as peças foram pesadas em uma balança e tomadas as dimensões para a determinação do volume. Dessa forma, obteve-se a densidade das lamelas, que é uma variável de utilização para cálculo do módulo de elasticidade pelo processo dinâmico utilizado no estudo.

O equipamento Stress Wave Timer, modelo 239A, da Metriguard, é composto por dois transdutores acelerômetros dispostos sobre o material a ser medido e um relógio registrador da velocidade da onda. O processo de medição desse equipamento consistiu na disposição da lamela entre os dois 
sensores com um vão livre de 3 metros; posteriormente, o relógio registrador foi zerado, liberando-se um pêndulo metálico que chocava com o sensor que emitia a onda na face transversal da lamela, fazendo com que a onda percorresse a lamela longitudinalmente até o receptor. Após a estabilização do valor de velocidade da onda, cerca de 3 a 5 repetições do processo, anotava-se a velocidade e prosseguia-se com o processo na próxima lamela. Foi determinado o MOE dinâmico em todas as lamelas que faziam parte do estudo através das equações de número 1 a 3.

Equação 1: $\quad V=\frac{d}{t}$

Equação 3:

Equação 2: $\quad \delta_{12 \%}=\frac{m}{v}$

Em que:

Equação 1: $\quad \mathrm{V}=$ velocidade de propagação da onda $(\mathrm{m} / \mathrm{s})$;

$\mathrm{d}=$ distância entre os sensores $(\mathrm{m})$;

$\mathrm{t}=$ tempo propagação da onda na lamela entre os dois sensores (microsegundos $\mathrm{X} 10^{6}$ );

Equação 2: $\quad \delta_{12 \%}=$ densidade a $12 \%$ de umidade $\left(\mathrm{kg} / \mathrm{m}^{3}\right)$;

$\mathrm{M} \quad=$ peso da lamela $(\mathrm{kg})$;

$\mathrm{v} \quad=$ volume da lamela $\left(\mathrm{m}^{3}\right)$;

Equação 3: $\quad$ MOEd = módulo de elasticidade dinâmico (MPa);

g = aceleração da gravidade $\left(9,80 \mathrm{~m} / \mathrm{s}^{2}\right)$.

Composição das vigas

Antes da aplicação do adesivo sob as lamelas, as vigas foram montadas sobre cavaletes, para se distribuir as lamelas quanto ao distanciamento entre as emendas e a disposição da classe de madeira densa nas partes da zona de tração e compressão da viga, ou seja, nas duas camadas inferiores e superiores, respectivamente. Já as peças classificadas como não densas foram colocadas nas duas camadas centrais da viga. Essa configuração de viga ficou denominada de método aleatório, sendo ensaiadas pelo método estático.

Aplicação do adesivo nas lamelas e prensagem das vigas

O equipamento para a aplicação do adesivo foi o sistema de rolos, que opera pelo contato com dois cilindros metálicos contendo ao seu redor uma capa de borracha com pequenas ranhuras em formato de "V" para facilitar a distribuição do adesivo na peça. Juntamente com os rolos maiores, têm-se dois outros rolos, chamados de rolos doutores, que têm a função de dosar a quantidade de adesivo a ser aplicado sobre a lamela.

As quatro lamelas que compõem o miolo das vigas de madeira laminada colada receberam adesivo em ambos os lados, e as tábuas das extremidades da viga somente em um dos lados, obtendo-se dessa forma uma gramatura dupla de $400 \mathrm{~g} / \mathrm{m}^{2}$.

Na homogeneização do adesivo de melamina ureia formaldeído foram utilizados 100 partes de resina para 20 partes de catalisador em uma temperatura ambiente de $25{ }^{\circ} \mathrm{C}$, podendo ficar em aberto, ou seja, com a cola aplicada e antes da prensagem, no máximo 100 minutos e no mínimo 10 minutos, proporcionando que sejam efetuadas as fases iniciais da colagem, como fluidez, transferência e penetração na estrutura capilar, deixando para que a umidificação completa e a solidificação só ocorram durante a prensagem das vigas. Sendo assim, foram preparados $7600 \mathrm{~g}$ de adesivo, sendo $6300 \mathrm{~g}$ de resina e $1300 \mathrm{~g}$ de catalisador.

$\mathrm{Na}$ prensa, as vigas foram colocadas em temperatura ambiente sob pressão de 12 Bar. Dessa forma, o processo foi concluído após 12 horas de exposição às variáveis. 


\section{Ensaios de rigidez}

Estimativa do MOE dinâmico das vigas estruturais de madeira laminada colada pelo método dinâmico

O MOE dinâmico das vigas estruturais de MLC foi calculado com base na distribuição das lamelas ao longo do composto, compreendendo 6 camadas de lamelas, sendo cada uma com sua respectiva identificação e valor de módulo de elasticidade dinâmico individual.

As duas lamelas superiores e as duas inferiores foram compostas por peças classificadas como densas através do método visual, e as duas lamelas centrais por peças não densas, entretanto, dentro das duas classificações, não houve uma distribuição das lamelas na viga por classes de rigidez, ou seja, dentro das duas classes, a distribuição foi aleatória. Dessa forma, denominou-se o módulo de elasticidade obtido por esse método de ALEATÓRIO, conforme já citado anteriormente. Para verificar a influência da distribuição das lamelas pela rigidez ao longo da viga, fez-se a estimativa do módulo de elasticidade através da distribuição das lamelas, de acordo com a região mais solicitada durante os ensaios, sendo a lamela com maior rigidez colocada na superfície inferior da viga, a segunda mais rígida na superfície superior, posteriormente a terceira na camada 4, a quarta na camada dois e assim sucessivamente. Esse procedimento foi denominado de módulo de elasticidade não aleatório.

Dessa forma, procedeu-se o cálculo do módulo de elasticidade das vigas (Equação 4), de acordo com as fórmulas apresentadas por Bodig; Jayne (1982).

Equação 4: $\quad M O E_{e}=\frac{1}{I} \times \sum_{i=1}^{n} M O E t^{i} \times I^{i}$

Em que: MOEe = módulo de elasticidade efetivo $\left(\mathrm{N} / \mathrm{mm}^{2}\right)$;

$\operatorname{MOEt}^{\mathrm{i}}=$ módulo de elasticidade da i-ésima lâmina na direção longitudinal $\left(\mathrm{N} / \mathrm{mm}^{2}\right)$;

$\mathrm{I}^{\mathrm{i}} \quad=$ momento de inércia da seção da i-ésima lâmina, em relação ao eixo baricêntrico da seção transversal da viga $\left(\mathrm{mm}^{2}\right)$;

I = momento de inércia de toda a seção da viga $\left(\mathrm{mm}^{4}\right)$;

$\mathrm{n} \quad=$ número total de lâminas.

A equação geral (Equação 5) para cálculo do momento de inércia de cada lâmina em relação à linha neutra, é obtida por:

Equação 5: $\quad I^{i}=I_{o}^{i}+A^{i} \times\left(d^{i}\right)^{2}$

Em que: $\mathrm{I}^{\mathrm{i}} \quad=$ momento de inércia da i-ésima lâmina em relação ao eixo baricêntrico da seção

transversal da viga $\left(\mathrm{cm}^{3}\right)$;

$\mathrm{I}_{\mathrm{o}}{ }^{\mathrm{i}} \quad=$ momento de inércia da i-ésima lâmina em relação a sua linha neutra, baricentral $\left(\mathrm{cm}^{4}\right)$

$\mathrm{A}^{\mathrm{i}} \quad=$ área da seção transversal da i-ésima lâmina;

$\mathrm{d}^{\mathrm{i}} \quad=$ distância entre o plano baricentral da viga laminada e a i-ésima lâmina.

Substituindo-se as equações 4 e 5 , tem-se a equação 6 :

Equação 6: $\quad M O E_{e}=\frac{1}{I} \times \sum_{i=1}^{n} M O E t^{i} \times\left(I_{O}^{i}+A^{i} \times\left(d^{i}\right)^{2}\right)$

As lâminas externas, de acordo com Bodig; Jayne (1982), contribuem mais sobre o valor do módulo de elasticidade efetivo da viga que aquelas lâminas colocadas próximas à linha neutra. Nesse caso, o posicionamento das lâminas de maior rigidez, ou de maior módulo de elasticidade, próximas à superfície tornam-se mais eficientes.

Determinação do MOE e do MOR obtidos a partir do ensaio estático das vigas

Na realização do ensaio estático das vigas para a obtenção dos valores de MOE, foi utilizado como referência o método descrito pela seção 4 da ASTM D-198 (1997), o qual visa à determinação das propriedades de flexão para vigas estruturais feitas de madeira sólida ou laminada, ou ainda componentes estruturais. Para a realização desse ensaio, foi utilizada uma máquina universal de ensaios (EMIC DL - 
30000), com capacidade máxima de carga de $30.000 \mathrm{~kg}$. Para a fixação dos pontos de reação, contou-se com uma barra de ferro de $15 \mathrm{~cm}$ de largura, $40 \mathrm{~cm}$ de altura e $500 \mathrm{~cm}$ de comprimento, sendo os apoios de reação presos na barra de ferro com garras do mesmo material.

A distância entre os pontos de apoio foi de $2700 \mathrm{~mm}$, sendo que a distância entre o ponto de reação até o ponto de aplicação de carga foi de $900 \mathrm{~mm}$, conforme prescrito na norma, que determina para a avaliação de propriedade de flexão um comprimento da zona de cisalhamento na razão entre 5:1 a 12:1, o qual corresponde à razão entre a distância entre o ponto de aplicação da carga e o ponto de reação mais próximo e a altura da viga. Sendo assim, na razão 900 para 122, obtém-se 7,4:1. Calculadas as distâncias na zona de cisalhamento, determinou-se a distância entre os pontos de aplicação de carga, que vem a ser a zona de flexão, que foi também de $900 \mathrm{~mm}$.

Para a medição da deformação na linha neutra da viga no decorrer do ensaio, utilizou-se um deflectômetro com capacidade de variação de deformação de $2,5 \mathrm{~cm}$ a partir do ponto inicial do ensaio. $\mathrm{O}$ deflectômetro foi posicionado na linha neutra no meio da viga, sendo fixado em um suporte de alumínio conhecido como YOKE, o qual estava fixado na linha neutra em dois pontos distanciados em $700 \mathrm{~mm}$ (L1), ou seja, $350 \mathrm{~mm}$ para cada lado do meio da viga.

Determinadas as distâncias entre os pontos de reação e os pontos de aplicação de carga, partiu-se para os ensaios que consistiram nos registros dos dados no programa Tesc da Emic, como altura e largura da viga, além da velocidade de aplicação da carga, a qual deveria ser suficiente para se obter a carga de ruptura em 10 minutos, de acordo com a norma, não menos que 6 minutos e nem mais que 20 minutos.

Sendo assim, após algumas simulações determinou-se uma velocidade de $0,6 \mathrm{~mm}$ de deformação por minuto, sendo a carga no limite proporcional atingida em média de 7 minutos de ensaio, e a carga máxima, no momento da ruptura, em aproximadamente 15 minutos.

O módulo de elasticidade da viga no ensaio estático foi calculado levando-se em consideração a diferença de deformação entre $40 \%$ e $10 \%$ da força máxima, adotando-se como referência para cálculo desse parâmetro a norma europeia EN 789 (1995). Dessa forma, aplicou-se a equação 7.

Equação 7: $\quad M O E=\frac{\left(F_{40 \%}-F_{10 \%}\right) \times\left(L_{1}\right)^{2} \times L_{2}}{16 \times\left(\operatorname{def}_{40 \%}-d e f_{10 \%}\right) \times I_{o}}$

Em que: $\mathrm{MOE} \quad=$ módulo de elasticidade $(\mathrm{MPa})$;

$\mathrm{F}_{40 \%} \quad=$ carga correspondente a $40 \%$ da carga máxima $(\mathrm{kgf}) ;$

$\mathrm{F}_{10 \%} \quad=$ carga correspondente a $10 \%$ da carga máxima (kgf);

$\mathrm{L}_{1} \quad=$ distância entre os pontos de apoio do $\mathrm{YOKE}(\mathrm{cm})$;

$\mathrm{L}_{2} \quad=$ metade do comprimento da zona de cisalhamento $(\mathrm{cm}) ;$

$\operatorname{def}_{40 \%}=$ deformação correspondente a $40 \%$ da carga máxima $(\mathrm{cm})$;

$\operatorname{def}_{10 \%}=$ deformação correspondente a $10 \%$ da carga máxima $(\mathrm{cm})$;

$\mathrm{I}_{\mathrm{o}} \quad=$ momento de inércia baricentral $\left(\mathrm{cm}^{4}\right)$.

O módulo de ruptura foi calculado com base na força máxima aplicada durante a realização do ensaio de flexão estática, incluindo no cálculo a zona de cisalhamento da viga e módulo de rigidez, conforme a equação 8 .

Equação 8: $\quad M O R=\frac{F_{M A X} \times L_{2}}{2 \times W}$

Em que: $\mathrm{MOR}=$ módulo de ruptura $(\mathrm{MPa})$;

$\mathrm{L}_{2} \quad=$ metade do comprimento da zona de cisalhamento $(\mathrm{cm}) ;$

$\mathrm{W} \quad=$ módulo de rigidez $\left(\mathrm{cm}^{3}\right)$.

\section{RESULTADOS E DISCUSSÕES}

\section{Módulo de elasticidade dinâmico das lamelas}

O método dinâmico de avaliação das propriedades de rigidez da madeira através do Stress Wave Timer depende diretamente da velocidade de propagação da onda acústica ao longo da peça ensaiada e da 
densidade do material. Quanto à velocidade de propagação da onda, pode-se dizer que quanto maior a velocidade, maior será o módulo de elasticidade da peça analisada, mantendo-se as demais variáveis inalteradas. Como pode ser observado na viga 5 da tabela 1 , as lamelas denominadas de M2 e M3 apresentam densidade igual a $426 \mathrm{~kg} / \mathrm{m}^{3}$, velocidades de $4,24 \mathrm{~m} / \mathrm{s}$ e $3,86 \mathrm{~m} / \mathrm{s}$ e consequentemente módulos de elasticidade diferenciados de $7.680 \mathrm{MPa}$ e $6.375 \mathrm{MPa}$, respectivamente.

Ao mesmo tempo, a velocidade de propagação da onda acústica também é influenciada pela quantidade de material lenhoso a ser atravessada no material que está sendo analisado, pois quanto maior a variável mencionada, menor é o tempo despendido desde o emissor até o receptor da onda. Sendo a velocidade a relação entre distância e tempo, mantendo-se a primeira variável inalterada e aumentando-se a segunda, diminui-se a velocidade. Mas, em contrapartida, de forma direta, quanto maior a densidade, maior é o módulo de elasticidade, tendo em vista que o módulo de elasticidade dinâmico é uma função do quadrado da velocidade de propagação da onda e da densidade.

Dessa forma, pode-se atribuir os diferentes índices de velocidade à presença de defeitos naturais, como a presença de nós, aos encaixes utilizados nas emendas dentadas tipo finger joit e ao adesivo utilizado na junção.

Com relação à densidade, pode-se destacar a influência da espécie a ser utilizada, do teor de umidade, que também influencia no desempenho do adesivo durante o seu processo de cura, da largura dos anéis de crescimento, da posição de retirada da peça ao longo do fuste da árvore, da porcentagem de lenho inicial e tardio, da diferenciação entre lenho juvenil e adulto, além de influências externas. Dessa forma, evidencia-se no cálculo da densidade (Tabela 1) uma grande heterogeneidade de valores com amplitude entre as peças de $383 \mathrm{~kg} / \mathrm{m}^{3}$ (viga 10 - lamela M1) e $560 \mathrm{~kg} / \mathrm{m}^{3}$ (viga 3 - lamela SI). Essa amplitude de variação é certamente derivada da origem das peças destinadas ao estudo, que contempla uma série de condições que já foram mencionadas, destacando-se a idade das árvores, a posição de retirada das peças e as influências externas.

A idade das árvores reflete a diferenciação entre os lenhos juvenil e adulto, sendo que o segundo é caracterizado como uma madeira mais densa, com traqueídes mais longos, paredes celulares mais espessas, alta porcentagem de lenho tardio, baixa porcentagem de nós, maior porcentagem de celulose, tornando a madeira mais flexível, menor ângulo fibrilar e consequentemente maior resistência mecânica. Considerando as características mencionadas, observou-se também que as peças foram retiradas em locais variados ao longo do fuste, próximo à casca ou à medula, e da base das árvores a toretes superiores, sem haver uma classificação da madeira direcionada ao uso estrutural.

Quanto às influências externas, destacam-se as condições de crescimento e os métodos silviculturais aplicados. O primeiro agrupa as variáveis de clima, solo (umidade e nutrientes), altitude, declividade, vento e espaçamento, entre outros; o segundo, adubação, poda, desbaste, composição de espécies etc.

A forma de aplicação da onda poderia ser um fator que diferenciasse a sua propagação, mas, durante a execução dos ensaios, ela manteve-se constante, colocando-se sempre o pêndulo de aplicação a uma mesma distância da peça, o que gera uma mesma intensidade de aplicação da onda em todas as peças ensaiadas.

Outro fator não analisado neste estudo que pode contribuir para a alteração da variável velocidade é o efeito das emendas entre duas peças coladas com adesivo, que pode vir a ser um obstáculo à passagem da onda ou um dissipador da onda ao longo da peça. Esse fator pode ser estudado em futuros experimentos.

Na tabela 1, observam-se os valores do MOE dinâmico para vigas produzidas de acordo com o sistema de classificação visual adotado pela empresa, em que se verifica que a lamela com maior rigidez deveria estar posicionada na camada inferior da viga, a segunda na parte superior, a terceira na segunda posição sentido de baixo para cima e assim sucessivamente.

Desse modo, observa-se que, nas dez vigas analisadas, nenhuma apresentava uma distribuição correta das lamelas, o que pode diminuir potencialmente a resistência e a rigidez geral da viga. Esse ponto será analisado no decorrer do estudo, comparando-se os valores de rigidez com a distribuição das lamelas sem/com a classificação através de ensaio dinâmico.

A distribuição das lamelas em dois grupos de rigidez na viga de MLC pelo método dinâmico é um fator determinante na rigidez da viga inteira, tendo em vista que as lamelas com maiores valores de MOE deveriam ser colocadas nas regiões mais solicitadas da viga, ou seja, nas zonas de tração e 
compressão, que correspondem à parte superior e inferior das vigas, respectivamente, pois somente a análise visual baseada na contagem de anéis de crescimento e na ocorrência de defeitos naturais das lamelas não foi suficiente para se alcançar os maiores valores de MOE na viga, sendo necessária a implementação de sistemas de classificação dinâmicos em todas as lamelas.

Tabela 1. Valores individuais de MOE dinâmico para as lamelas utilizadas na produção de vigas.

Table 1. Individual values for dynamic MOE for lamellas used in production of beams.

\begin{tabular}{|c|c|c|c|c|c|c|c|c|c|}
\hline Viga & Lamela & $\begin{array}{c}\text { Densidade } \\
\left(\mathrm{kg} / \mathrm{m}^{3}\right)\end{array}$ & $\begin{array}{c}\text { Velocidade } \\
(\mathrm{m} / \mathrm{s})\end{array}$ & $\begin{array}{l}\text { MOE } \\
\text { (MPa) }\end{array}$ & Viga & Lamela & $\begin{array}{c}\text { Densidade } \\
\left(\mathrm{kg} / \mathrm{m}^{3}\right)\end{array}$ & $\begin{array}{c}\begin{array}{c}\text { Velocidade } \\
(\mathrm{m} / \mathrm{s})\end{array} \\
\end{array}$ & $\begin{array}{l}\text { MOE } \\
\text { (MPa) }\end{array}$ \\
\hline \multirow{6}{*}{01} & SS & 506 & 4.26136 & 9.186 & \multirow{6}{*}{06} & $\mathrm{SS}$ & 447 & 4.68019 & 9.788 \\
\hline & M1 & 467 & 4.14365 & 8.022 & & M1 & 401 & 3.69458 & 5.475 \\
\hline & M2 & 440 & 3.74065 & 6.153 & & M2 & 463 & 3.76884 & 6.579 \\
\hline & M3 & 419 & 3.61011 & 5.466 & & M3 & 397 & 3.72671 & 5.514 \\
\hline & M4 & 410 & 4.04585 & 6.724 & & M4 & 435 & 3.48028 & 5.265 \\
\hline & SI & 424 & 3.96825 & 6.685 & & SI & 481 & 3.83632 & 7.086 \\
\hline \multirow{6}{*}{02} & SS & 539 & 4.24929 & 9.740 & \multirow{6}{*}{07} & SS & 505 & 3.87097 & 7.565 \\
\hline & M1 & 425 & 3.89610 & 6.459 & & M1 & 491 & 4.26136 & 8.928 \\
\hline & M2 & 430 & 3.82166 & 6.281 & & M2 & 443 & 3.71287 & 6.104 \\
\hline & M3 & 416 & 4.31035 & 7.735 & & M3 & 446 & 3.55872 & 5.647 \\
\hline & M4 & 404 & 3.53774 & 5.058 & & M4 & 425 & 3.98406 & 6.754 \\
\hline & SI & 456 & 3.93701 & 7.068 & & SI & 459 & 3.68098 & 6.220 \\
\hline \multirow{6}{*}{03} & SS & 477 & 4.41826 & 9.740 & \multirow{6}{*}{08} & SS & 557 & 4.14246 & 9.692 \\
\hline & M1 & 443 & 3.97878 & 6.459 & & M1 & 459 & 4.24929 & 8.289 \\
\hline & M2 & 407 & 3.93185 & 6.281 & & M2 & 426 & 3.74532 & 5.983 \\
\hline & M3 & 439 & 3.71747 & 7.735 & & M3 & 435 & 3.61882 & 5.692 \\
\hline & M4 & 406 & 3.59281 & 5.058 & & M4 & 439 & 3.94218 & 6.826 \\
\hline & SI & 560 & 3.96302 & 7.068 & & SI & 485 & 3.68550 & 6.595 \\
\hline \multirow{6}{*}{04} & SS & 473 & 4.65839 & 10.271 & \multirow{6}{*}{09} & SS & 489 & 4.02685 & 7.939 \\
\hline & M1 & 493 & 3.59281 & 6.359 & & M1 & 426 & 3.81194 & 6.198 \\
\hline & M2 & 404 & 3.45622 & 4.828 & & M2 & 401 & 3.79747 & 5.784 \\
\hline & M3 & 459 & 4.24929 & 8.289 & & M3 & 441 & 3.98936 & 7.015 \\
\hline & M4 & 413 & 3.82166 & 6.036 & & M4 & 436 & 3.75940 & 6.158 \\
\hline & SI & 484 & 3.68098 & 6.565 & & SI & 463 & 3.35196 & 5.204 \\
\hline \multirow{6}{*}{05} & SS & 451 & 4.17246 & 7.851 & \multirow{6}{*}{10} & SS & 439 & 4.13793 & 7.512 \\
\hline & M1 & 428 & 3.71287 & 5.908 & & M1 & 383 & 4.24328 & 6.892 \\
\hline & M2 & 426 & 4.24328 & 7.680 & & M2 & 436 & 3.95257 & 6.807 \\
\hline & M3 & 426 & 3.86598 & 6.375 & & M3 & 468 & 3.88601 & 7.071 \\
\hline & M4 & 439 & 3.58423 & 5.636 & & M4 & 423 & 3.86598 & 6.329 \\
\hline & SI & 495 & 4.41177 & 9.628 & & SI & 482 & 4.19580 & 8.494 \\
\hline
\end{tabular}

SS: lamela da superfície superior; M1, M2, M3, M4: lamelas centrais no sentido descendente; SI: lamela da superfície inferior.

Mesmo a classificação visual utilizada pela empresa sendo insuficiente para fim estrutural, apresentase como um método importante para uma pré-classificação no momento do destopo dos defeitos e na escolha das peças que serão unidas em cada uma das lamelas, evitando-se a efetivação dos ensaios dinâmicos em todas as peças destopadas, passando para essa atividade depois da lamela pronta, ou seja, depois de as peças serem emendadas, evitando perda de tempo e produzindo aumento no rendimento da operação de classificação.

O sistema de classificação através do Stress Wave Timer é simples, prático e de resultado imediato, podendo ser utilizado em qualquer parte da empresa, seja na floresta ou na indústria, tendo em vista que é um equipamento leve e portátil, podendo determinar a velocidade de propagação tanto em árvores quanto em peças de madeira serrada, alterando-se somente os dispositivos de emissão e recepção da onda. O conjunto desses fatores torna o sistema atraente frente a outros métodos dinâmicos que são de grande porte, alto investimento e manutenção, apesar de contarem com softwares sofisticados.

Em estudo realizado por Fagundes; Szücs (1998), nota-se que após a classificação estabeleceram-se 3 classes de vigas com módulo de elasticidade maiores, médios e menores, os quais 
foram distribuídos em 5 modelos de vigas. Os resultados do experimento demonstraram que não houve diferença estatística na resistência das vigas analisadas, mas a dispersão dos valores de MOE foi pequena, variando de $7.581 \mathrm{MPa}$ a $7.630 \mathrm{MPa}$. Entretanto, no presente estudo a dispersão dos valores de MOE dinâmico foi de 4.828 MPa a 10.271 MPa. A amplitude de valores de módulo de elasticidade dinâmico encontrada neste estudo certamente não apresentaria as mesmas considerações se fosse aplicada no estudo comparativo, reforçando a necessidade de uma classificação não destrutiva durante a composição das vigas estruturais de madeira laminada colada pelas lamelas emendadas.

Evidencia-se, portanto, a necessidade da classificação para peças estruturais, podendo-se dizer que quanto maior o número de grupos de rigidez em que for subdividida a atividade, maior será a probabilidade de se aumentar a resistência e a rigidez da viga. Mas deve-se atender a questão de operacionalidade dentro das empresas, que pode dificultar o processo, diminuindo o rendimento.

\section{Módulo de elasticidade dinâmico e estático das vigas}

A partir da determinação do MOE dinâmico individual das lamelas que fizeram parte da viga, foi estimado o módulo de elasticidade dinâmico da viga inteira, com base na classificação visual realizada pela empresa e também através da distribuição das lamelas de acordo com a qualidade de rigidez desejada para a realização de comparações, pois, de acordo com Zangiácomo (2003), as propriedades de rigidez de vigas de MLC obtidas nos ensaios de flexão estática podem ser influenciadas pela disposição das lâminas ao longo da altura da seção transversal. Vigas com distribuição não aleatória de lâminas podem apresentar propriedades de rigidez superiores às de vigas montadas com distribuição aleatória de lâminas.

Tabela 2. Módulo de elasticidade das vigas de MLC.

Table 2. Modulus of elasticity of the glulam beams.

\begin{tabular}{lcccc}
\hline \multirow{2}{*}{ Viga } & \multicolumn{2}{c}{ MOE dinâmico $($ MPa) } & $\begin{array}{c}\text { MOE estático } \\
\text { (MPa) }\end{array}$ & $\begin{array}{c}\text { MOR } \\
\text { (MPa) }\end{array}$ \\
\cline { 2 - 3 } 1 & Aleatório & Não aleatório & 8.011 & 18 \\
2 & 8.195 & 8.492 & 9.567 & 37 \\
3 & 8.251 & 8.585 & 6.857 & 20 \\
4 & 8.495 & 8.568 & 8.528 & 28 \\
5 & 8.320 & 8.860 & 8.152 & 31 \\
6 & 8.492 & 8.667 & 7.341 & 31 \\
7 & 8.057 & 8.151 & 5.903 & 30 \\
8 & 7.590 & 8.192 & 8.272 & 19 \\
9 & 8.393 & 8.769 & 7.965 & 30 \\
10 & 6.996 & 7.524 & 8.725 & 34 \\
\hline Média & 8.181 & 8.232 & 7.932 & 28 \\
\hline Variância & 8.097 & 8.404 & 1050040,77 & 43,07 \\
\hline Desvio padrão & 218111,11 & 154518,67 & 1024,71 & 6,56 \\
\hline Valor máximo & 467,02 & 393,09 & 9.567 & 37 \\
\hline Valor mínimo & 8.495 & 8.860 & 5.903 & 18 \\
\hline
\end{tabular}

MOE Dinâmico Aleatório: através do SWT conforme distribuição utilizada pela empresa, ou seja, sem distribuição das lamelas por rigidez dentro das duas classes de densidade. MOE Dinâmico Não aleatório: através do SWT, conforme distribuição por MOE em cada lamela, sendo que a lamela com maior valor de MOE foi utilizada na superfície inferior, a segunda na superior, a terceira na lamela denominada M4, a quarta na M1 e assim sucessivamente, em função das zonas externas serem as mais solicitadas durante a aplicação da carga.MOE Estático: variável determinada por meio estático em Máquina Universal de Ensaios.

Analisando-se a tabela 2, observa-se que em todas as vigas de madeira laminada colada com uma classificação e distribuição adequada das lamelas obteve-se um ganho médio de rigidez de $4 \%$, mas podendo atingir $8 \%$ de ganho, como na viga 7, em que se obteve um MOE de 7.590 MPa, separando-se as lamelas em duas classes de rigidez através do método visual, e $8.192 \mathrm{MPa}$, com MOE estimado através do Stress Wave Timer, distribuindo-se as peças através da rigidez encontrada pelo processo, tendo em vista que as regiões mais solicitadas da viga receberiam as lamelas com maior módulo de elasticidade, e a região próxima à linha neutra, as lamelas com menores valores. A distribuição das lamelas independe do adesivo que está sendo utilizado, mas diretamente das dimensões e das características anatômicas das peças que estão sendo trabalhadas. 
Neste estudo, optou-se pela divisão das peças em duas classes de qualidade, densa e não densa, sendo a primeira para as duas extremidades das vigas e a segunda para as quatro camadas internas, sem se ter a preocupação com os valores de rigidez dentro das classes. Sendo assim, a rigidez foi reduzida quando comparada com o que se poderia obter de rigidez do material através da distribuição adequada das lamelas.

Os valores de módulo de elasticidade que expressam a rigidez das vigas foram determinados a partir da carga e deflexão da viga no limite proporcional, apresentando uma grande dispersão entre os resultados encontrados, o que evidencia a influência dos fatores relacionados à madeira.

Efetuando-se uma análise comparativa entre os métodos de obtenção do MOE de elasticidade dinâmico e estático, verificou-se que a correlação entre as variáveis foi muito baixa, pois o coeficiente encontrado foi de 0,2867. Mesmo assim, desenvolveu-se uma análise de regressão (Figura 1), na qual se observa a dispersão dos valores encontrados em cada um dos ensaios.

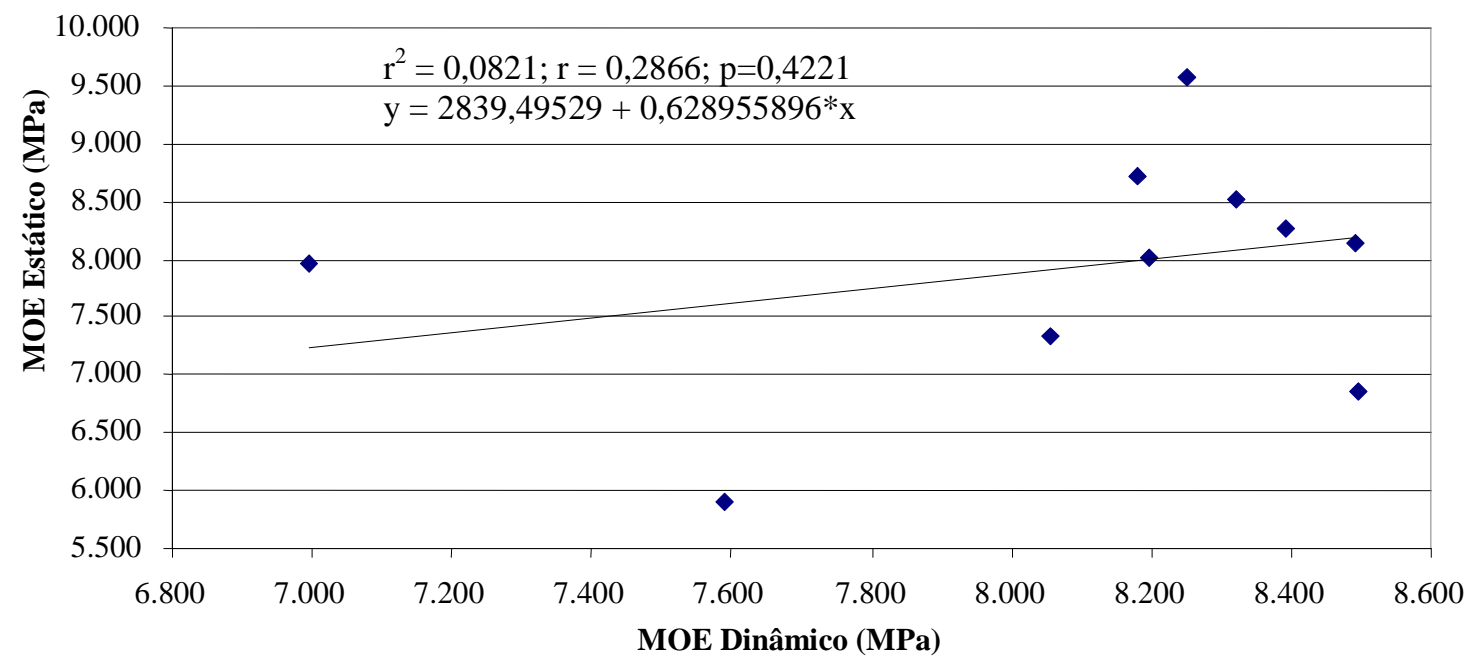

Figura 1. Gráfico de correlação linear entre os valores de módulo de elasticidade dinâmico (estimado) e estático (real) medido em vigas laminadas coladas.

Figure 1. Graph linear correlation between the values of dynamic elasticity module (estimated) and static (real) measured in glulam beams.

Dessa forma, evidenciou-se que MOE dinâmico explica somente 8,21\% do MOE estático, sendo o restante derivado de outras variáveis, como matéria-prima, condições de confecção das vigas e procedimentos utilizados nos ensaios. Com relação aos procedimentos de ensaio, foram utilizadas formas diferenciadas de obtenção do MOE: o dinâmico foi baseado na viga inteira, e o estático com aplicação dupla de carga. Evidencia-se também que a análise dinâmica foi desenvolvida com base nos valores individuais de cada lamela, sem levar em consideração a composição da viga com o adesivo na colagem das faces. $\mathrm{Na}$ análise estática, tem-se a presença efetiva do adesivo entre as faces das lamelas. Dessa forma, mesmo não havendo relação direta entre o MOE estimado da viga e o real, reforça-se a importância dos ensaios dinâmicos, pois, classificando-se a madeira em grupos de rigidez, privilegia-se o aumento da rigidez das vigas durante a sua utilização na estrutura e/ou durante os ensaios mecânicos em laboratório, assegurando um melhor aproveitamento da madeira e a maior segurança das vigas em uso.

O valor do módulo de ruptura é apenas comparativo, não sendo influenciado pela relação vão e altura da viga. A análise dos valores do MOR está apresentada na tabela 2, onde se observa que a média foi de $28 \mathrm{MPa}$ e que a amplitude dos valores foi de 18 a $37 \mathrm{MPa}$, tendo como consequência direta uma variância de 43,07. Efetuando-se uma análise de correlação entre o módulo de elasticidade estático (real) e o módulo de ruptura das vigas, encontrou-se um coeficiente de 0,257 , ou seja, a correlação entre as duas variáveis foi baixa.

O valor de carga máxima e o do módulo de ruptura são influenciados por fatores relacionados à madeira e a fatores externos, como o processo de composição da viga. Entre esses fatores estão os encaixes dentados, que influenciam significativamente esses valores, seja o comprimento dos dentes, seja as distâncias entre os dentes na viga ou a falta de pressão durante a efetivação do encaixe. 


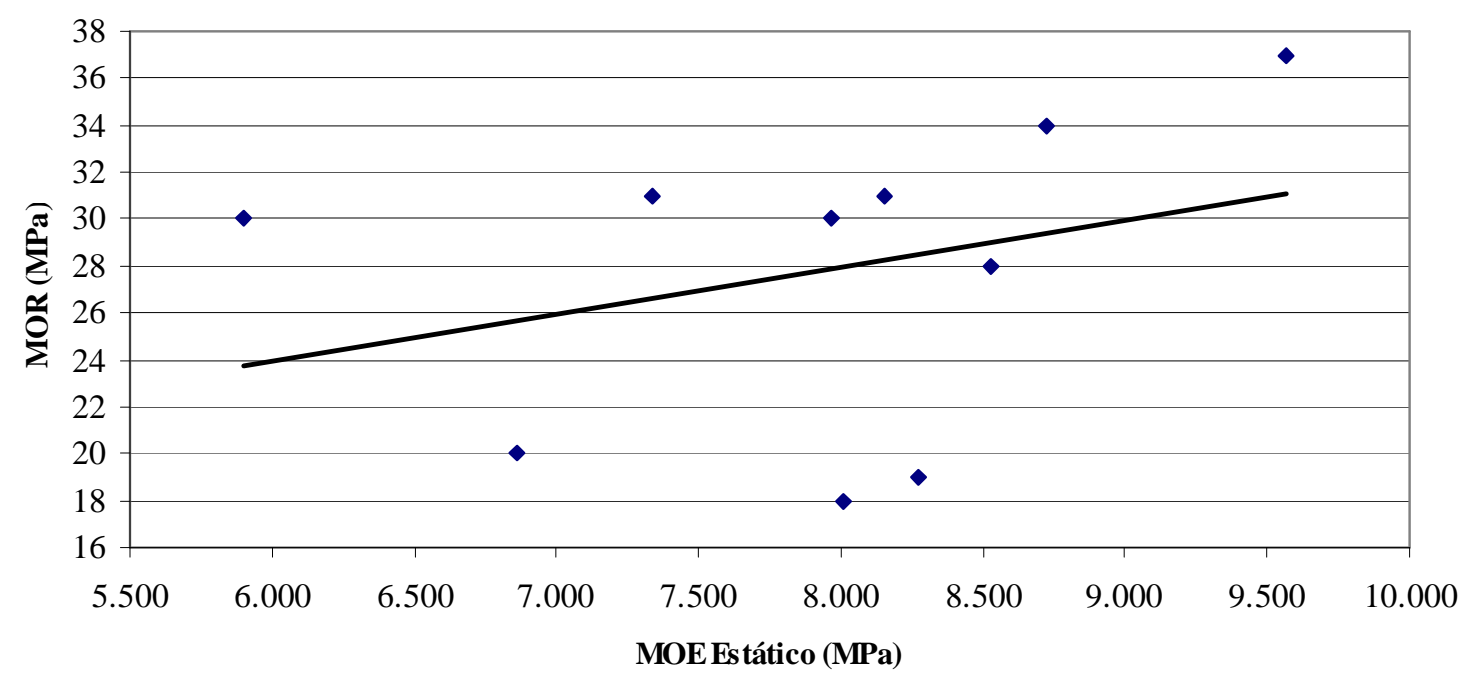

Figura 2. Gráfico de relação linear entre os valores de módulo de ruptura e de elasticidade estático (real) medido em vigas laminadas coladas.

Figure 2. Graph of linear relationship between the values of bending strength and elasticity static (real) measured in glued laminated beams.

No presente estudo foram observados três tipos de ruptura: por tração na camada inferior da viga, região oposta à aplicação da carga; nas regiões com a presença de agentes redutores de resistência, como os encaixes e a presença de nós; e em menor escala na região de cisalhamento na linha de cola ao longo do eixo longitudinal da viga, onde se tem a presença do adesivo. Saliente-se que as rupturas nas vigas ensaiadas foram observadas nos estágios finais da deformação plástica, sem grandes variações em relação ao limite proporcional.

Andrigheto et al. (2006) realizaram ensaios de flexão estática com dois pontos de aplicação de carga em madeira laminada colada de Pinus spp. com $3150 \mathrm{~mm}$ de comprimento e $315 \mathrm{~mm}$ de altura, sendo composta por 12 lâminas classificadas de acordo com análise visual e propriedades físicas/mecânicas da madeira. Os resultados demonstraram nas vigas com 1/4 de lâminas com qualidade superior MOE médio de $12.695 \mathrm{MPa}$; para as vigas com 1/6 de lâminas com qualidade superior MOE de 10.252 MPa; já quando foram utilizadas lâminas invertidas nas regiões de maior esforço, o MOE foi de $11.685 \mathrm{MPa}$.

Estudo realizado por Nielsen (1998) com vigas laminadas coladas de Eucalyptus spp., com seção retangular de $10 \times 23 \mathrm{~cm}$ e adesivo resorcinol formaldeído, demonstrou que as vigas formadas com peças de material genético de Eucalyptus grandis de árvores com idade média de 9 anos, de duas procedências distintas, apresentam um MOE de $10.885 \mathrm{MPa}$ para densidade média de $630 \mathrm{~kg} / \mathrm{m}^{3}$ e $11.607 \mathrm{MPa}$ para densidade média de $680 \mathrm{~kg} / \mathrm{m}^{3}$. Já o material da segunda procedência apresentou MOE de $10.171 \mathrm{MPa}$ para a primeira densidade e $12.730 \mathrm{MPa}$ para a segunda.

Comparando-se os resultados do presente estudo com os estudos mencionados, verifica-se que, quando comparados os ensaios em MLC tanto de Pinus spp. como de Eucalyptus spp., os resultados foram inferiores na variável estudada, sendo que o maior valor de MOE estático do presente estudo foi de 9.567 MPa. Assim, deve-se enfatizar que os valores de módulo de elasticidade encontrados para as vigas de MLC podem ser aumentados com o efetivo controle dos níveis de defeitos da madeira admitidos para a classificação.

\section{CONCLUSÕES}

- O sistema de classificação visual utilizado na seleção de peças de madeira para a confecção de vigas estruturais de Madeira Laminada Colada foi insuficiente para se atingirem os valores máximos de módulo de elasticidade das vigas.

- As variações dos valores de módulo de elasticidade dinâmico das lamelas foram afetadas diretamente pela amplitude dos valores de massa específica e de velocidade de propagação da onda. 
- O posicionamento das lamelas por meio de métodos dinâmicos de classificação, como o Stress Wave Timer, têm como consequência o aumento da rigidez da viga.

- O presente estudo evidenciou que houve uma baixa correlação entre o módulo de elasticidade dinâmico e o estático das vigas de madeira laminada colada.

- O modelo de regressão linear não se mostrou adequado para o estabelecimento de predições do MOE real de vigas, obtidos em ensaios estáticos, a partir de valores estimados pelo método de disposição de lamelas em classes de rigidez.

\section{REFERÊNCIAS}

ABNT (Associação Brasileira de Normas Técnicas). NBR 7190: Projetos de Estruturas de Madeira. Rio de Janeiro: ABNT, 1997, p. 107.

ANDRIGHETO, R.; SZÜCS, C. A. Estudo comparativo entre madeira laminada colada e madeira laminada colada multicolada. São Pedro (SP): Anais do $10^{\circ}$ EBRAMEM - Encontro Brasileiro em Madeiras e em Estruturas de Madeira, 2006.

AMERICAN SOCIETY FOR TESTING MATERIALS. ASTM D3737 (1996). Standard Test Method Practice for Establishing Stresses for Structural Glue Laminated Timber (Glulam). Philadelphia, PA, 1996.

AMERICAN SOCIETY FOR TESTING MATERIALS. ASTM D198. Standard Test Methods of Static Tests of Lumber in Structural Sizes. Philadelphia, PA, 1997.

AMERICAN SOCIETY FOR TESTING MATERIALS. ASTM D245. Standard Practice for Establishing Structural Grades and Related Allowable Properties for Visually Graded Lumber. Philadelphia, 1998.

BAUER, L. A. F. Materiais de construção: a madeira como material de construção. Rio de Janeiro: Livros Técnicos e Científicos, 1985. cap. 14, p. 36-48.

BODIG, J.; JAYNE, B. A. Mechanics of wood and wood composities. New York: Van Nostrand Reinhold, 1982.

CARRASCO, E. V. M. Resistência, elasticidade e distribuição de tensões nas vigas retas de madeira laminada colada (MLC). São Carlos: Tese da Escola de Engenharia de São Carlos - Universidade de São Paulo, 1989.

CARREIRA, M. R. Critérios para classificação visual de peças estruturais de Pinus sp. São Carlos: Dissertação apresentada à Escola de Engenharia de São Carlos da Universidade de São Paulo, 2003, p. 182.

CHUGG, W. A. (1964). Glulam: the theory and pratice of the manufacture of glued-laminated timber structures. London: Ernest Benn, 423 p.

DEUTSCHES INSTITUT FÜR NOMUNG. DIN 68140 - Wood Finger - Jointing. Berlim - Alemanha, 1971.

EN 789: 1995. Estruturas de Madeira - Métodos de teste - Determinação das propriedades mecânicas de painéis derivados de madeira. European Stardard (versão portuguesa), Bruxelas, 1995.

FAGUNDES, G. S.; SZÜCS, C. A. Composição racional de vigas de madeira laminada colada de pinus. Florianópolis: Anais do VI EBRAMEM - Encontro Brasileiro em Madeiras e em Estruturas de Madeira, p. 277-288, 1998.

FIORELLI, J. Estudo teórico e experimental de vigas de madeira laminada colada reforçadas com fibra de vidro. São Carlos: Tese apresentada à Área de Interunidades em Ciência e Engenharia de Materiais da Universidade de São Paulo, 2005, p. 108.

FREAS, A. D.; SELBO M. R. Fabrication and design of glued laminated wood structural members. Technical Bulletin n. 1069, Madison: US. Departament of Agriculture, 1954. 
HENRIQUE DE JESUS, J. M. Estudo do adesivo poliuretano a base de mamona em madeira laminada colada (MLC). São Carlos: Tese de Doutorado da Escola de Engenharia de São Carlos Universidade de São Paulo, 2000.

LAHR, F. A. R. Sobre a determinação de propriedades de elasticidade da madeira. São Carlos: Tese apresentada a Escola de Engenharia de São Carlos da Universidade de São Paulo, 1983.

MACEDO, A. N.; CALIL JÚNIOR, C. Caderno de Engenharia de Estruturas - Estudo de Emendas Dentadas em Madeira Laminada Colada (MLC): Avaliação de Método de Ensaio - NBR 7190/1997. São Carlos: EESC-USP, Universidade de São Paulo - Escola de Engenharia de São Carlos Departamento de Engenharia de Estruturas, n. 7, 1999, p. 23.

MATOS, J. L. M. Produção de vigas de madeira laminada colada e sua utilização. Apostila da Disciplina de Produção de Vigas Laminadas do Curso de Pós-Graduação em Engenharia Florestal da Universidade Federal do Paraná, 2000, p. 54.

Estudos sobre a produção de painéis estruturais de lâminas paralelas de Pinus taeda L. Curitiba: Tese apresentada ao Setor de Ciências Agrárias da Universidade Federal do Paraná, 1997, p. 117.

MOODY, R. C.; HERNANDEZ, R. Engineered Wood Products - A Guide for Specifiers, Designers and Users. Chapter 1: Glued - Laminated Timber. Madison, Wisconsin: USDA Forest Service, Forest Products Laboratory, 1997, p. 1-39.

NAHUZ, M. R. A.; FRANCO, N.; FIGUEIROA, F. M. Z. Uso estrutural da madeira de eucalipto: a experiência do IPT. Belo Horizonte: Anais do $1^{\circ}$ Seminário Internacional de Produtos Sólidos de Madeira de Alta Tecnologia, p. 126-133, 1998.

NATTERER, J. Quality criteria for timber design. In: International Timber Engineering Conference, London. Proceedings, v. 2, 1991, p. 19-26.

NIELSEN, I. R. Utilização da madeira comercial do híbrido de Eucalyptus urophylla S.T. Blake X Eucalyptus grandis Hill ex Maiden na confecção de vigas laminadas coladas. Curitiba: Dissertação apresentada ao Curso de Pós-Graduação em Engenharia Florestal, do Setor de Ciências Agrárias da Universidade Federal do Paraná. 1998, p. 109.

PINHEIRO, R. V.; LAHR, F. A. R. Emprego da madeira do gênero Pinus na construção de estruturas de cobertura. São Carlos: EESC-USP, Universidade de São Paulo - Escola de Engenharia de São Carlos Departamento de Engenharia de Estruturas, n. 10, 1999, p. 1-27.

SELBO, M. L. Effect of joint geometry on tensile strength of finger joints. Forest Products Journal, p. 390-400, 1963.

SOUTHERN PINE INSPECTION BUREAU (1994). Standard Grading Rules for Southern Pine Lumber. Pensacola, Fla.

SOUTHERN PINE INSPECTION BUREAU (1999). Graders Manual for Boards and 2 Dimension. Pensacola, Fla.

SZÜCS, C. A. Influência da variação da densidade da madeira sobre o seu módulo de elasticidade. In: IV EBRAMEM, 1992, São Carlos/SP. Anais do IV EBRAMEM. São Carlos/SP: IBRAMEM, 1992. v. 1. p. 13-18.

Artigo de painéis - madeira laminada colada (MLC). Departamento de Engenharia Civil/Laboratório de Experimentação em Estruturas. Disponível no site <http://www.remade.com.br/ madeiras/paineis_mlc.php>. Acesso em 07/03/06 às 10:15 h.

TARGA, L. A.; BALLARIN, A. W.; BIAGGIONI, M. A. M. Avaliação do módulo de elasticidade da madeira com uso de método não destrutivo de vibração transversal. Jaboticabal: Engenharia Agrícola, v. 25, n. 2, mai/ago 2005, 291-299. 
ZANGIÁCOMO, A. L. Emprego de espécies tropicais alternativas na produção de elementos estruturais de madeira laminada colada. São Carlos: Dissertação apresentada à Escola de Engenharia de São Carlos, da Universidade de São Paulo, 2003, p. 82. 